\title{
Long Range Temperature Forecasts
}

\author{
A Method of Comparing Weather Records with a View to Predicting Future Conditions \\ By Frank S. Wood
}

IN 1916, the writer, while plotting a chart of the annual mean temperature for Boston, Massachusetts, happened to use a ruled paper divided into groups of twelve lines. As a result of that occurrence, when the chart had been finished which included the records from 1871 to that date, it was observed that a high temperature recurred at the end of every group of twelve lines and that this was the highest tem perature during that period. This was the proof of temperature cycles. Taking this evidence as conclusive, further study made it obvious that in this movement of temperature was concealed the natural law which governed temperature changes. If the law could be found, long range forecasting of temperature would not only be possible but practicable. From that time on, an intimate analysis of the records was made with the object of perfecting a method of forecasting which should be sound and mathematical and wholly free from the personal equation as well as the element of guesswork. The writer believes that such a system is now demonstrated in which the forecasts of temperature for a long time ahead, will now be verified in over 80 per cent. of cases, while further study and research will largely increase this percentage of verifications. The reasons for such belief are that forecasts made a year ahead, by months, have already been verified accurately as above. As the value of an invention consists not in the idea but in its reduction to practise and the results attained thereby, so the value of this method of forecasting is proved by the accuracy with which forecasts are verified. The proof of the pudding is in the eating. However, much or little the reader may agree with the reasoning of the writer, the obtaining of unheard of results and having forecasts verified, month after month, is or ought to be sufficient evidence to convince the most skeptical that long range forecasts are being made. It is not within the range of possibilities for chance to enable a mathematica calculation to be correct in a long series of sequentia forecasts. If the figures were based upon false prem ises, no three forecasts, in sequence, could by any possibility be verified. When twelve consecutive months have their forecasts verified, he who would refer the results to chance can only be classified among those who close their eyes and deny that there is light.

At first, it only seemed within the range of prob ability to me that it would be likely to foreoast year of extreme heat and cold which might be verified but an intimate analysis of the chart of temperature largely broadened the range of practical probabilities. For example, once it was determined that there was an orderly march of temperature from a high point to a low point, covering a period of years, many of which were known a long time in advance, it became equally clear that a more intimate study, of the monthly temperatures of specific years, ought to determine what months in those years were likely to be prominent in infiuencing temperature in a given direction. Thereafter, it was carefully worked out by months, on the same basi principle which had given the verification by years, and it was found equally true with monthly temperature namely, that months of extreme heat or cold were correctly indicated in more than 80 per cent. of forecasts. rectly indicated in more than 80 per cent. of forecasts.
This ought to be good enough, as a start, for any new This ought to be good enough, as a start, for any new
method. At any rate, these are the results thus far achieved. The forecasts make good. Throughout this account, the data used and the section covered by it is that of the Boston forecast district, unless otherwise specified, therefore in the event that a statement is made which is not clear in its meaning, it always refers to Boston and vicinity.

It may be of interest to describe the steps by which the method of making long range forecasts of tem perature was worked out. As already noted, the first step was the charting of the temperature by yearly means, which figures are obtained by averaging the monthly means of each year; the latter are in turn obtained by averaging the daily mean temperatures of each month. It was first observed that the chart of annual mean temperature showed that the temperature had a constant variation; that from a highest point in a group of years there was an orderly downward movement to a lowest point and a re turn to another highest point, and so on. Then it was noted that each group of years extending from one high point to the next was very similar in general character to the other groups. Then it was obvious that there was a temperature period or cycle, during which lowest point in that period and then rose to another high point within 12 years. As there are twelve months in the year so there are 12 years in the temperature period. At least, that is the nearest that it can be measured. It has been noted to occur in 9 year and again in 13 years; the average for the last 11 years beginning in 1801 was 11.3 years. If, under cer tain circumstances, a record exceeds 11 years, it re

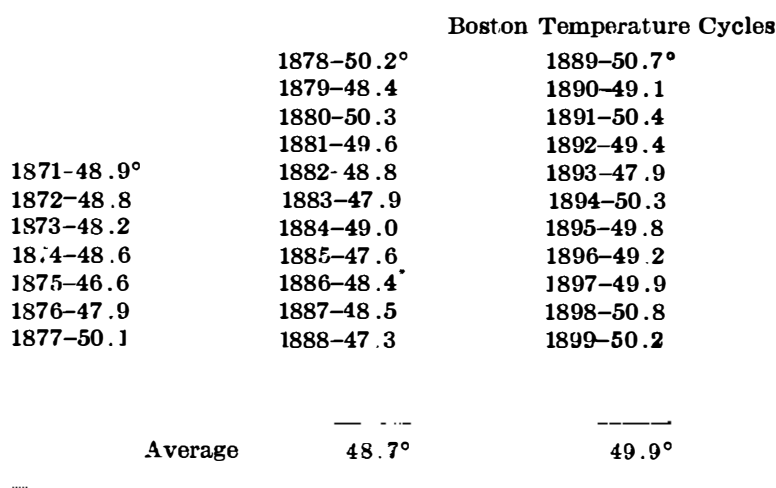

quires 12 calendar years to complete the period. The final year of the rise which completes the cycle, serves. when completed, as the first year of the next cycle. The next feature of the temperature chart to be com prehended was that the orderly march of temperature through each cycle was by means of constantly varying reciprocating movements. From the highest point in each cycle, the temperature takes a step down, followed by a step up, another step down and another step up, and so on. A step may cover one year or several years but the steps all lead to the same end namely, from the highest point to the lowest point and back again to a new highest, with 12 years as the measuring stick of the average cycle. The temperature data was then tabulated by groups numbered from to 11. respectively, the first year of each cycle being averaged with the first year of all the other cycles, which gave a normal temperature for that first or hot test year of the cycle, and so on with all the othe years. As the result of this composite column of figures, we have a table representing the normal temperature of each year in the cycle. This normal temperature varies every year; starting at the highest, it reaches the lowest point the fifth year, as a rule, reacting therefrom the two succeeding years and declining again to a low point the eighth year of the cycle. The temperature may be lower the eighth year than the fifth or it may not be quite so low, but both year may be looked forward to with confidence as being relatively cold years. From the eighth year, there is a rapid rise to a new high point beginning the next cycle. This description embodies the skeleton or frame work of a new science in temperature forecasting. The fiesh and blood of the system is supplied by what follows. The brain and nerves will only be annexed by furthe study and research upon these lines and for many years to come.

Several new facts are established by the foregoing, foremost among which is the cycle of temperature. While it is of great importance to be able to accurately forecast years of extreme heat and cold, it seems to $\mathrm{m}$ to be of no less importance to establish a standard of measurement for temperature so as to be able to demonstrate whether or not any perceptible changes are taking place and, if so, what those changes may con sist of. Moreover, the fixing of a normal temperature for each year of the cycle is a great step in advance. As used in describing temperature by the Weather Bureaus, the normal is the average of all the years of record. Instead of being the expected temperature, it is that which occurs the most seldom. On the contrary, the above described method of obtainin a table of normal temperatures results in obtaining set of figures within the true meaning of the word, and any departure from the normal in a given year of the cycle is, with rare exceptions, but a fraction of degree. For example, the expected or normal temperature for the year 1917, in Boston, by the table befor mentioned was 48.2 degrees; the actual record was 47.9 degrees; while the so-called Weather Bureau normal or mean was 49.4 degrees. Again, using the 12-year measuring stick, it is found that the temperature of Boston has been slowly but surely increasing. By the law of averages, Boston annual mean temperature has increased $11 / 2$ degrees in 36 years or at the rate of $1 / 2$ degree for each 12 years. The monthly changes are even more striking and will be elsewhere described. Below is given the table of annual mean temperature, for Boston, arranged in cycles and in regular years of each cycle, and the last column of which is the normal, or temperature to be expected, in each year of the cycle.

$\begin{array}{lccc} & & \text { Year } & \text { Normal } \\ 1900-50.8^{\circ} & 1913-52.3^{\circ} & 1 \text { st } & 51.0^{\circ} \\ 1901-49.0 & 1914-49.7 & 2 \text { d } & 49.1 \\ 1902-49.6 & 1915-51.2 & 3 d & 50.4 \\ 1903-49.5 & 1516-49.7 & 4 \text { th } & 49.5 \\ 1904-47.1 & 1917-47.9 & 5 \text { th } & 48.1 \\ 1905-49.1 & & 6 \text { th } & 49.0 \\ 1906-50.0 & & 7 \text { th } & 49.2 \\ 1907-48.7 & & 8 \text { th } & 48.5 \\ 1908-51.2 & & 9 \text { th } & 49.0 \\ 1909-50.5 & & 10 \text { th } & 49.4 \\ 1910-50.8 & & 11 \text { th } & 49.6 \\ 1911-50.9 & & & \\ 1912-50.5 & & & \end{array}$

$1911-50.9$
$1912-50.5$

$49.8^{\circ}$

The figures of this table are the official data published by the Boston Weather Bureau. When plotted upon a chart their relations to one another and to the (ycles which they represent become obvious. See Chart. While the normal figure for the fifth year is now 48.1 degrees, in the paragraph preceding the table, I gave the figure upon which the forecast was based hefore the temperature of 1917 was known.

It should be carefully noted that the first year temperature for each cycle has always exceeded the previous highest mark. This is another bit of evidence that the temperature of Boston is increasing. There is no getting away from that fact which can neither he evaded nor avoided.

Applying the forecast to the last column of figures, it will be seen that the normal temperature to be expected for 1918 is 49 degrees or about a degree higher than the record of 1917 . Special attention is called to the fact that in every cycle, thus far, the changes from the first to the fifth year of the cycle have been regular. From the high point there has been, in each instance, a step down, a step up, and another step down, the latter occupying two years. From this year on, there is greater irregularity in variations.

Without going farther, the natural law governing temperature changes was revealed by the chart and the table above given. In a nutshell, it may be briefly stated as follows:

Extremes of heat occur the first year of the cycle, followed by reciprocating changes until the fifth year when extremes of cold occur. After reacting from this extreme another extreme of cold occurs the eighth year followed by either a reciprocating rise or a sharp rise to the beginning of the next cycle.

This law governs temperature changes in a zone several hundred miles wide and in which Boston appears to be well within its boundaries. It does not govern sections far removed both north and south of this zone but the changes in these far-removed zones are governed by modifications of this law similar to the law of climate and modifications thereof due to latitude and altitude. In other words, the forecasting of temperature by long range methods is not simple. The estab. lishment of a fundamental principle for the Boston zone of efficiency does not establish that principle or any other principle for other zones. Each zone has a character and law of its own, upon the successful discovery of which depends the application of the principle to forecasts and verifications thereof.

Boston is one of the few if not the only Weather Bureau station in its zone that has records which are reliable to indicate changes of temperature covering substantial periods of time. Other stations in other cities almost everywhere in the United States have experienced one removal after another where the thermometer exposures have been so changed as to completely veil any real change of temperature. It has been actually proved by demonstration, in Chicago, that a difference of 1.7 degrees resulted in a single removal. The New York station is now 414 feet above the street and has resulted in lowering the temperature 
about 1 degree. Unless temperature is recorded under similar conditions and exposures, the records are rendered worthless for purposes of truthful comparison.

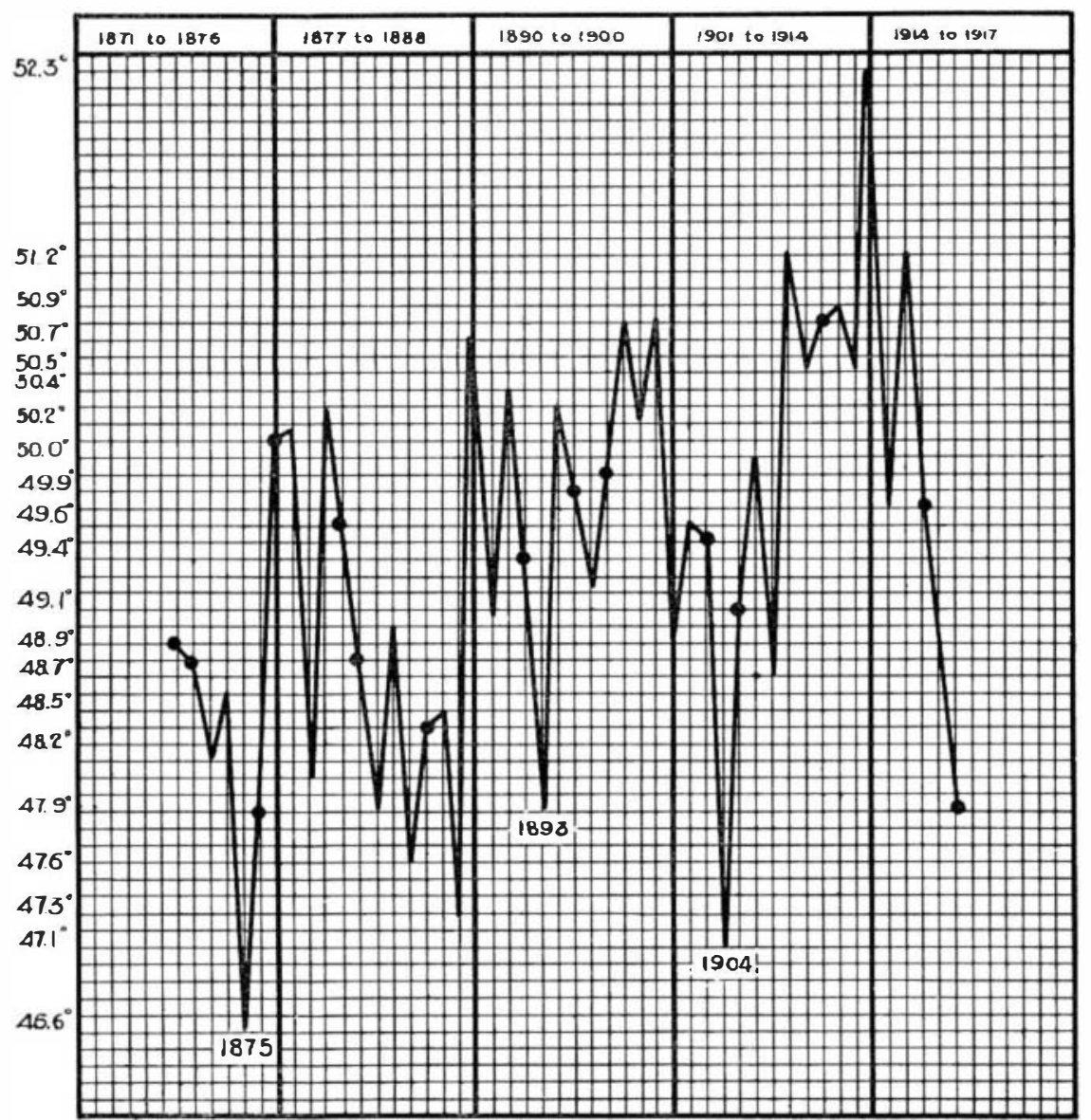

Annual mean temperature at Boston, Mass.

Therefore, when it is understood that the change of it may readily Boston is but $11 / 2$ degrees in 36 years, of New York and Chicago possess when a removal in one year off sets all the real variation in true tempera. ture. Until the Government adopts a policy of establishing Weather Bureau stations nearer the groun and where the thermometer exposures may be constantly the same, its records are absolutely worthless to posterity if any comparative deductions are desired. The temperature data of New York, Philadelphia Washington, Buffalo, Detroit, Chicago, St. Louis, and many other cities, have been examined, charted, tabulated, and compared with Boston and with one another. Corrections for removals have been impossible, but enough irregularities were established and accounted for to support the facts established at the Boston station. I make no hesitation in stating that they corroborate, in general, the determinations derived from the Boston data. The charts vary in details but indicate much that cannot be demonstrated owing to the unfortunate temperature changes due solely to removals to higher buildings and lower temperatures than before and vice versa. The Boston thermometers have had the same exposure since the Weather Bureau was established and only one removal to its present quarters in 1885 , therefore its records have an unusual value which are excelled by no other station in the United States. But this was unknown to the writer until after years of study and research.

Having pointed out the factors which express the law of long range forecasting of temperature changes, many of my readers have no doubt already formed the conclusion that the truth is out and anybody can do his own forecasting. But we are dealing with yearly temperature which takes 365 days to record one entry and in which there is little satisfaction in being able to make a successful forecast. Let us step out of the year into the month and see what happens in our new surroundings.

We now know that there is a certain zone in which relatively high temperatures may be expected at the end and beginnings of each cycle and that relatively low temperatures may be expected between the high points One might anticipate that these annual changes would proportionately influence each month of any specified year of the cycle. If so, that anticipation would be in error. Such simplicity, if it obtained, would long ago have been observed. The character of temperature is complex, not simple, but has a character based upon natural law just as well as the 12 different motions of the Earth. The backbone of that character is the vertebra comprising the normal temperature of each cycle year. As each year of the cycle differs from every other year, so each month of each year differs from every other month of that year and every other year. The complexity now becomes so apparent that the wonder is that it may ever be mastered. However, the complications are more apparent than real as will pres-

ently be seen. Applying the keynote of temperature change to each month of the year, as in the table of annual temperature, and another table is provided for each month which shows wherein it is in tune with the annual change and wherein lies the discord. In thi table we have the normal temperature of that month during each year of the cycle. The figure which represents the expected temperature of each year of that month is the approximate temperature to be recorded in the future. There are exceptions, occasionally, which are reasonably accounted for and with more accurate study and observation may, in time, be successfully anticipated. The method is by no mean perfected but it is even now as successful as any

\begin{tabular}{|c|c|c|c|c|c|c|}
\hline & \multicolumn{4}{|c|}{ Boston Tabulation for December } & \multicolumn{2}{|c|}{ Year Normal } \\
\hline & $1878-30^{\circ}$ & $1889-38^{\circ}$ & $1900-33^{\circ}$ & $1913-38^{\circ}$ & 1st & \\
\hline & 1879-32 & $1890-26$ & $1901-32$ & $1914-30$ & $2 \mathrm{~d}$ & 30.0 \\
\hline & $1880-27$ & $1891-40$ & $1902-28$ & 1915-34 & $3 \mathrm{~d}$ & 32.3 \\
\hline & $1881-39$ & $1892-30$ & $1903-29$ & 1916-33 & 4th & 32.7 \\
\hline $1871-28^{\circ}$ & $1882-30$ & $1893-30$ & $1 \subseteq 04-26$ & $191 ;-24$ & 5th & 27.6 \\
\hline 1872-23 & $1883-29$ & 1894-32 & 1905-35 & & 6th & 29.7 \\
\hline $1873-32$ & $1884-34$ & $1895-36$ & $1906-29$ & & 7th & 32.7 \\
\hline 1874-31 & $1885-33$ & $1896-30$ & $1907-3$ & & 8th & 32.7 \\
\hline $1875-30$ & $1886-28$ & $1897-34$ & 1908-33 & & 9th & 31.2 \\
\hline 1876-22 & $1887-32$ & $18 \div 8-32$ & 1909-31 & & 10th & 29.2 \\
\hline $1877-36$ & $1888-35$ & $1899-36$ & $1910-28$ & & 11 th & 33.7 \\
\hline & & & $1911-31$ & & & \\
\hline & & & $1912-38$ & & & \\
\hline
\end{tabular}

method of weather forecasting, which promises much by future development. In forecasting the temperature of any month, it is of no special value to predict the actual temperature to a degree. The information de sirable and valuable is to know if extreme cold is to be experienced, if extreme heat will take place, if average or seasonable temperature will occur, and finally if a temperature between the average and eithe extreme is likely to appear. This establishes five different degrees of temperature which are of practica benefit to the public, which may be classified as follows Severe cold (for that month); moderately cold, seasonable temperature, moderately warm, and extreme heat (for that month). Provided that any degree of

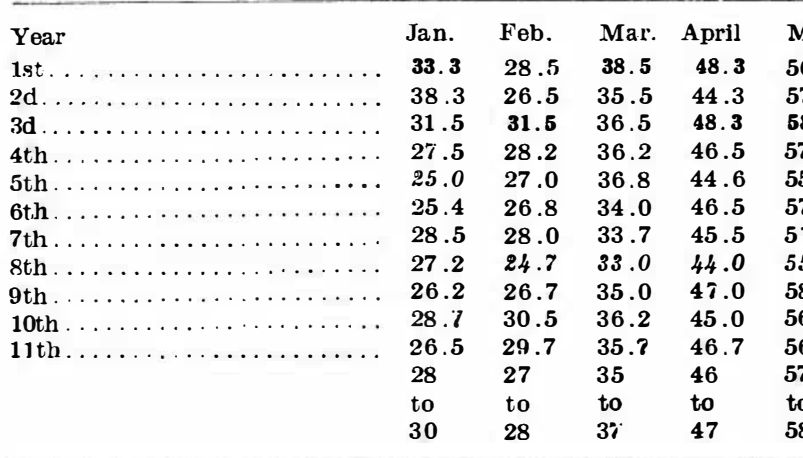

temperature is forecast which brings it within the above classification, there can be no doubt that the forecast may be checked as verified. To illustrate, a table of monthly mean temperatures for December is submitted

This month corresponds, in its extremes, with the annual table. The first year averages the mildest and the fifth year as the coldest. In the column of normal temperatures, it is seen that $\mathbf{3 4 . 8}$ degrees is the highest average but the actual highest was 39 in 1911, consequently any temperature as high or higher than 34.8 degrees would be extreme heat (for that month). On the other hand, the lowest average (normal) is 27.6 degrees but the actual lowest was 22 degrees in 1876, therefore any temperature as low or lower than 27.6 degrees would be extreme cold (for that month). It is obvious that a temperature from 30 to 31 degrees would be seasonable while any temperature between these figures and either extreme would be proportionately and moderately warm or cold, as the case might be. As the normal figures change with each cycle, it is only practicable to compare those in the table with the actual figures from 1913 to 1917 incluusive. Note the result:

The first year, 1913, extreme heat was forecast and the normal figure was 33.6 degrees at that time. The actual record verified the forecast, being 5 degrees above the normal heat extreme. The second year, seasonable temperature was forecast and was verified by the record; the third year, moderately warm was forecast and verified; the fourth yeur, ditto; the fifth year, extreme cold was forecast and verified, the actual record being over 4 degrees colder than the normal up to that year.

In all probability, we have seen the coldest Deecember, the past winter, which will be had until 1928, when another December of severe cold is forecast. Here is a concrete example of the long range to which temperature may be forecast.

In contrast with the large percentage of verifications in December forecasts, the month of January, at present, has the most exceptions. The normal figures, for January, forecast extremely cold weather for both the fifth and sixth years. The forecast for the fifth year was in error, the actual record being slightly higher than seasonable; but the sixth year fell into line again, being 4 degrees below the normal for that cold year and only 1 degree above the lowest ever recorded.

CHARACTERISTICS OF TEMPERATURE CYCLES BY YEARS AND MONTHS

The following table furnishes the index numbers for Boston, Mass., for each month in each year of the cycle

The figures in bold face type are the months indicating extreme heat and the italic figures are the months indicating extreme cold. These refer to the relative heat and cold of each special month with regard to the records for that month. Each figure is the mean for that month and year of all the cycles thus far recorded from 1871 to March, 1918.

Index numbers which correspond to seasonable tem. peratures need no correction. Those indicating extremes require correction to turn the index numbers into actual degrees expected, as will be elsewhere described.

The table below given is typical of the Zone No. 1 stations which extends broadly from Montreal, Canada, to Washington, D. C., Boston being well within both northern and southern limits. It is very closely related to the North and Middle Atlantic States, classified as Area No. 1, in 1918, by the U. S. Weather Bureau. While many of its characteristics are found as far west as St. Paul, Minn., important changes are found at Buffalo, N. Y., and still more in Chicago, Ill. Along the northern boundary of this zone, certain months in years which will be specified appear to be dominated by the influence of the next zone north of it; while along the southern border a similar influence is noted as modifying certain months to harmonize with the different character of the zone just south of Zone No. 1.

\begin{tabular}{|c|c|c|c|c|c|c|c|}
\hline June & July & Aug. & Sept. & Oct. & Nov. & Dec. & Annual \\
\hline & 72.8 & 69.8 & 63.5 & 54.3 & 44.3 & 34.8 & 50.1 \\
\hline 66.0 & 71.0 & 69 & & & 40.3 & 30.0 & \\
\hline 65.5 & 69.8 & 69.5 & 65.5 & 53.5 & 42.5 & 32.3 & 50.4 \\
\hline 63.8 & 71.7 & 69.5 & 64.7 & 54.2 & 42.0 &.$i$ & 49.5 \\
\hline 65.6 & 71.8 & 71.2 & 61.0 & 53.4 & 39.0 & 7.6 & 48.1 \\
\hline 68.2 & 73.7 & 69.5 & 62.7 & 52.0 & 41.7 & 29.7 & 49.0 \\
\hline 66.8 & 70.2 & & & & & & 49.2 \\
\hline 66.0 & 72.2 & 69.2 & 62.5 & 51 & & 2.7 & 48.5 \\
\hline 65.5 & 72.2 & 69.5 & 63.2 & 52.7 & 40.7 & 1.2 & 49.0 \\
\hline 67.2 & 73 & & & & & 29.2 & 49.4 \\
\hline 67.2 & 72.0 & 70.0 & 62.5 & 52.5 & 42.7 & 33.7 & 49.6 \\
\hline & 71 & 69 & & 53 & 42 & & \\
\hline & & & to & to & to & & \\
\hline & & & 64 & 54 & 43 & & \\
\hline
\end{tabular}


FTRST CYCLE YEAR

Referring to the table, it will be seen that the index number shows that the annual mean temperature is noted for extreme heat in the first year of the cycle. While the annual index number indicates the genera character of temperature for the year, the monthly index numbers show what months are most infiuential in producing this highest annual mean temperature. It will be noted that the months of January, March, April, June, November and December are the only one giving large excesses of heat. Of the others, February and September are seasonable or average; Ma and August, are moderately cool; and July and October are moderately warm. These characteristics appea to be common to all places within Zone No. 1 .

$$
\text { SECOND CYCLE YEAR }
$$

The second year of the cycle shows a substantia drop in annual temperature, especially noteworthy in those months which showed the greatest excess of hea in the first year. This is one of the few years chiefiy noted for its moderate monthly temperatures. The exceptional months are April which is usually very coo and October which shows extreme warmth for that month. This characteristic, however, is not common to all places within Zone No. 1, as this is one of th years when substantial modifications occur. Thus, in the north, Montreal for example, extreme heat occurs in May as well as October and extreme cold in November. In Washington, a cool September occurs. A places between Boston and these other two cities, there are mixed conditions partaking of the character of both.

\section{THIRD CYCLE YEAR}

In the third cycle year, an upswing in annual temperature occurs, in which the months of 'February, April, May and September are conspicuous examples while July and August are very cool. Other month are either moderately warm or seasonable. There is less excess of heat along the southern border of Zone No. 1 and in Washington. On the other hand, Montreal which had its warmest May a year earlier, now has only moderate heat in that month but has a greater excess in March. The other months are in harmony with the general characteristics of the zone.

\section{FOURTH CYCLE YEAR}

This year brings another drop in temperature simila to that of the second year, with a warm May and a cold June as conspicuous extremes. The only other noteworthy variation is a warm August along the southern border of the zone.

\section{FIFTH CYCLE YEAR}

The fifth year brings a continuation of the down swing which, as a rule, results in the coldest annual temperature of any year in the cycle. It brings ex treme cold for January, May, September, Novembe and December and moderate cold for April. Only one month, August, brings excess of heat, the other month being seasonable.

\section{SIXTH CYCLE YEAR}

In this year, a substantial rise of temperature occurs from the low point of the fifth year. Only one month January, indicates extreme cold; March, August and October indicate moderate cold; May brings moderate heat while June and July show extreme heat, and the other months are seasonable in the central section of the zone. This is another year which brings modifications along its borders. In the north, the extreme heat indicated for the central section is modified to seasonable conditions; while in the southern part of the one extreme heat in May is added to the other summer heat.

\section{SEVENTH CYCLE YEAR}

With the exception of a cool July and a hot September, the seventh year of the cycle is devoid of extremes in the central part of Zone No. 1. But at both northern and southern extremities the month of June brings extreme heat. There is a gradual warming up tendency in most months this year throughout this zone, excepting extreme cold in the southern part during March.

\section{EIGHTH CYCLE YEAR}

This year brings the final reaction to low temperature, for the cycle, it being a toss-up whether this year or the fifth year will prove to have the lowest annual temperature. It is a remarkable fact, however, that none of the months registering extreme cold in the flth year are found in the extreme column this year, possibly excepting May. Now, we find February, March, April, August and October bringing an excess of cold, with May from moderate to extreme cold. In the south portion of the zone a moderately warm January, July and December occur.

\section{NINTH CYCLE YEAR}

The ninth year is like the sixth year in annual temperature but the central section of the zone has no months of extremes. The winter months are warmer and the summer cooler with seasonable temperature throughout, excepting a moderately cold January. In the southern part of the zone, however, exceptions occur in which extreme cold is indicated in February and August; while in the northern part June brings extremely cool weather.

\section{TENTH CYCLE YEAR}

The tenth year is substantially warmer than the preceding but there are few extremes. February and July show excesses of heat; while in the south portion, only, December shows an excess of cold.

\section{ELEVENTH CYCLE YEAR}

A further warming up takes place this year which is Prequently the last year of the cycle, although there are exceptions. The north and central portions are usually without any extremes. An occasional exception, however, occurs which brings excessive heat to New York City in June

The foregoing table and description establishes general rule for long-range forecasts which are verifie in about 75 per cent. and to which there are exception in about 25 per cent. of indications. One illustration of an exception will furnish an example of the kind of work which is still required in order to increase the percentage of verifications. In January of the fift year, extreme cold is indicated for the No. 1 Zone It was verified in the northern part of the zone but the cold did not extend as far south as Boston. The sixth year, moderate cold was indicated throughou the zone; but extreme cold was the record. The conclusion is that extreme cold is to be expected in January the fifth year of the cycle but it may not come until the sixth year at central and southern points in the zone. There is good ground for predicting the exception, based upon what part of the year the turn of the cycle takes place. If it happens in the first part of the year, extreme cold comes in January of the fifth year; on the other hand, if the turn of the cycle comes in the last part of the year, then extreme cold comes in January of the sixth year.

\section{SEASONABLE TEMPERATURE}

It may be well to define what is meant by seasonable temperature. The Weather Bureau calls the average temperature seasonable; but in many places and in many months, the average is constantly changing. For instance, in Boston, the average temperature of the month of January is 28. The average for the first twelve years of the record was 26.6. The average for the last 12 years was 29.8 , and within the last 14 years it has been as high as 31 ; while it has not been below 28 during the last 20 years. It is clear, then, that the range of seasonable temperature is from 28 to 30 . For other months than January, seasonable temperature have been arrived at in the same way.

\section{CORRECTIONS}

Since the last cycle began in 1913, which was the first year, it is simple to trace the temperature through any year. One thing which cannot yet be anticipated is the number of years in the cycle. The preceding cycle contained 13 years and that was the first cycle within the records of the Weather Bureau which contained more than 11 years. Whether the present cycle will resume the average of 11 years or whether it will be less, remains to be seen. If it goes back to the 11-year period, 1924 will be the first year of the next cycle, but this may not be certainly known before the next year of minimum sunspots is determined.

It has already been noted that this tabulation shows, in rare instances, that one place will have an extremely cold month a certain year of the cycle while another place will have extreme cold the same month in the year following. Similar instances have been noted with regard to months of extreme heat. Should further tabulations increase the number of instances of this character, it is readily seen that this feature alone will result in anticipating exceptions to the rule to a large degree of efficiency. But this is not the only source of information, in this respect, although it is a very important one which should be taken advantage of at the earliest possible moment.

One peculiar fact in regard to the January index numbers is that notwithstanding the wide range of seasonable temperature, from 28 to 30 , only 3 months in the cycle come within this range.

Another fact derived from the study of February variations is that the temperature of that month has grown colder while other winter, spring and fall months have grown warmer. February is now the coldest winter month when averaged in 12-year periods hrough the central and southern portions of Zone No. 1, and extending to places far south.

August is another month showing a decline in tem erature.

In conclusion, the following forecast is given for the balance of this year and the first half of the year 1919. The figures given are for Boston but the wordin of the forecast for each month applies equally to all places within the Zone No. 1 subject to border modifications already described.

1918 FORECAST :

May, moderately warm-60; June, extreme heat (for that month) - 70; July, extreme heat-74 to 77; August, unusually cool-67; September, seasonable-62; October, moderately cool-50; November, seasonable 42 ; December, moderately cold-27. 1919 FORECAST :

January, moderately cold-27; February, seasonable -28; March, moderately cold-29; April, moderately cool-44; May, seasonable-58; June, seasonable -67.

\section{SCIENTIFIC AMERICAN SUPPLEMENT}

$$
\text { Founded } 1876
$$

NEW YORK, SATURDAY, MAY 18, 1918

\section{Published weekly by Munn \& Company, Incorporated
Charles Allen Munn. Trusidgont: Frodirilck Converse Beach all at 233 Broad way, New York
arearson}

Entered at Post Office of New York, N. Y.. as Second Class Matter Opyright 1917 by Munn \& Co., Inc.

The Scientific American Publications

Scientiflc American Supplement. (established 1876) per year 85.00 The combined subscription rates and rates to forelgn countrios,
including Canada, will be furnished upon application.
Remit by postal or express money order, bank draft or check.

Munn \& Co., Inc., 233 Broadway, New York

The purpose of the Supplement is to publish the more important announcements of distinguished technologists, to digest significant articles that appear in European publications, and altogether to reflect the most advanced thought in science and industry throughout the world.

\section{Back Numbers of the Scientific American} Supplement

Sopplements bearing a date earlier than January 1 st, 1917, can be supplied by the H. W. Wilson Company, 958-964 University Ave., Bronx, New York, N. Y. Please order such back numbers from the Wilson Company. Supplements for January 1st, 1917, and subsequent issues can be supplied at 10 cents each by Munn \& Co., Inc., 233 Broadway, New York.

WE wish to call attention to the fact that we are in a position to render competent services in every branch of patent or trade-mark work. Our staff is composed of mechanical, electrical and chemical experts, thoroughly trained to prepare and prosecute all patent applications, irrespective of the complex nature of the subject matter involved, or of the specialized, technical, or scientific knowledge required therefor.

We also have associates throughout the world, who assist in the prosecution of patent and trade-mark applications filed in all countries foreign to the United States.

Branch Office:

25 F Street, N. W. Washington, D. C. 233 Broadway,
New York, N. Y.

\section{Table of Contents}

Problems of Atomic Structure-II.-By Sir J. J. Thomson. . 30 The Delicious Fruits of Actinidi

Gas Heated Isothermal Room.....................
Anomalies of the Animal World-Part X.-By Dr. R. W.

Shufeldt. -7 illustrations..................................
odine and Iodine-Thiourea as subtractive Reducers for

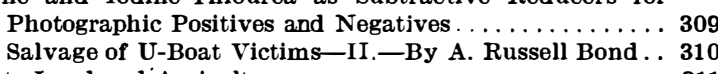
Waste Land and Agriculture.

Ocean Venison. -7 illustrations.

Alloys to Withstand Internal Air Pressure..

Extracting Vaporous Constituents of Coal Ga.

The Ether Ball.-By N. Johanssen

Storage Battery or Reversible Battery? ................

Pickering on Residual Affnity.-By Spencer U. Pickering

ncreasing the Evaporation of Steam Boilers.-By Carl Hering. - 3 diagrams.

Tunnels vs. Bridges

Long-Range Temperature Forecasts.-By Frank $\mathrm{S}$. Wood... 318 